\title{
The '2012 European guideline on the diagnosis and treatment of gonorrhoea in adults' recommends dual antimicrobial therapy
}

M Unemo (magnus.unemo@orebroll.se) ${ }^{1}$, on behalf of the European STI Guidelines Editorial Board ${ }^{2}$

1. WHO Collaborating Centre for Gonorrhoea and other Sexually Transmitted Infections, Department of Laboratory Medicine,

Microbiology, Örebro University Hospital, Örebro, Sweden

2. www.iusti.org/regions/Europe/euroguidelines.htm

\section{Citation style for this article:}

Unemo M, on behalf of the European STI Guidelines Editorial Board. The '2012 European guideline on the diagnosis and treatment of gonorrhoea in adults' recommends dual antimicrobial therapy. Euro Surveill. 2012;17(47):pii=20323. Available online: http://www.eurosurveillance.org/ViewArticle. aspx?Articleld $=20323$

The '2012 European guideline on the diagnosis and treatment of gonorrhoea in adults' was launched on November 15, 2012 on the website for European STI Guidelines and is also accepted for publication in International Journal of STD \& AIDS [1]. The newly launched guideline, an updated version of the 2009 European (IUSTI/WHO) guideline on the diagnosis and treatment of gonorrhoea in adults [2], provides up-todate guidance on:

- broader indications for testing and treatment of gonorrhoea;

- the introduction of dual antimicrobial therapy. The recommended treatment for uncomplicated Neisseria gonorrhoeae infections of the urethra, cervix, rectum and pharynx, when the antimicrobial sensitivity is unknown, is a combination of ceftriaxone $500 \mathrm{mg}$ and azithromycin $2 \mathrm{~g}$;

- recommendation of test of cure in all gonorrhoea cases to ensure eradication of infection and identify emerging resistance;

- recommendations to identify, verify and report failures with recommended treatment regimens [3-5].

Further details regarding recommended diagnostics, recommended and alternative treatment regimens, treatment of ceftriaxone-resistant gonorrhoea, management of additional types of gonococcal infections or complications and of specific patient groups are also available in the newly launched guidelines [1].

Gonorrhoea remains a major public health problem. In 2008, the World Health Organization (WHO) estimated 106 million cases among adults worldwide (3.4 million in the WHO European region) [3]. In the European Union (EU), gonorrhoea is the second most commonly reported bacterial sexually transmitted infection (STI) after chlamydia [4]. However, the incidence is underestimated because of suboptimal diagnostics, case reporting and surveillance.
During recent years, resistance has been identified to the recommended extended-spectrum cephalosporins cefixime and ceftriaxone, the mainstay of first-line antimicrobial monotherapy for gonorrhoea [2]. Several treatment failures with cefixime and a few with ceftriaxone were recently verified in Europe, together with the first three extensively drug-resistant (XDR) $N$. gonorrhoeae strains with high-level ceftriaxone resistance [5,6]. In this developing situation, the WHO [3] and the European Center for Disease Prevention and Control (ECDC) [4] published global and regional action/response plans, respectively, to combat and mitigate the spread of multidrug-resistant gonorrhoea. This emergence of resistance has prompted revision of national and international treatment/management guidelines.

\section{References}

1. Bignell $C$ and Unemo $M$, on behalf of the European STI Guidelines Editorial Board. 2012 European guideline on the diagnosis and treatment of gonorrhoea in adults. Int J STD AIDS. Forthcoming. (http://www.iusti.org/regions/Europe/ pdf/2012/Gonorrhoea_2012.pdf)

2. Bignell C, IUSTI/WHO. 2009 European (IUSTI/WHO) guideline on the diagnosis and treatment of gonorrhoea in adults. Int J STD AIDS. 2009;20(7):453-7.

3. World Health Organization (WHO), Department of Reproductive Health and Research. Global action plan to control the spread and impact of antimicrobial resistance in Neisseria gonorrhoeae. Geneva: WHO; 2012. p. 1-36. Available from: http://whqlibdoc.who.int/publications/2012/9789241503501_ eng.pdf

4. European Centre for Disease Prevention and Control (ECDC). Response plan to control and manage the threat of multidrugresistant gonorrhoea in Europe. Stockholm: ECDC; 2012. p. 1-23. Available from:http://www.ecdc.europa.eu/en/ publications/Publications/1206-ECDC-MDR-gonorrhoearesponse-plan.pdf

5. Unemo M and Nicholas RA. Emergence of multidrug-resistant, extensively drug-resistant and untreatable gonorrhoea. Future Microbiol. 2012;7(12):1401-22.

6. European Centre for Disease Prevention and Control (ECDC). Gonococcal antimicrobial susceptibility surveillance in Europe 2010. Stockholm: ECDC 2012. Available from: http://ecdc. europa.eu/en/publications/Publications/1206-GonococcalAMR.pdf 